Journal of Thermal Engineering, Vol. 6, No. 5, pp. 677-696, October, 2020

Yildiz Technical University Press, Istanbul, Turkey

\title{
ENHANCEMENT IN THERMO-HYDRAULIC PERFORMANCE OF MICROCHANNEL HEAT SINK WITH SECONDARY FLOWS OF LEAF VENATION PATTERN
}

\author{
V. P. Gaikwad*, S. S. Mohite, S. S. Shinde, M. L. Dherange
}

\begin{abstract}
A new microchannel heat sink (MCHS) design comprising of secondary channels which connect neighboring primary channels are numerically analyzed to study their thermo-hydraulic characteristics. The inclusion of secondary channels in the continuous walls results in disturbance of thermal and hydrodynamic boundary layers which leads to drop in boundary layer thickness. Number of such secondary channel on either side of main channel will cause the flow to be continuously in developing state. The new MCHS are tested for heat flux range of 65 Watt per sq. cm to 200 Watt per sq.cm and cooled by water flowing at Reynolds number ranging from 650 to 1300 . Compared to conventional MCHS, the thermal performance of new MCHS is higher but at the cost of pressure drop. The overall enhancement factor of the new design which is a function of Nusselt number and pressure drop of enhanced MCHS and conventional MCHS is 1.4 to 1.85 .
\end{abstract}

Keywords: Microchannel, Primary channel, Secondary flow, Enhancement factor

\section{INTRODUCTION}

The development of Micro-fabrication technologies has resulted in very small and compact electronic devices which created a requirement of removing large quantity of heat generated by such electronic devices from the small space. Use of microchannels for electronic cooling was first put forward by Tuckerman and Pease [1] since then, huge amount of work has been done on MCHS for electronic cooling. Apart from the optimization of the microchannel dimensions, a number of techniques were explored to improve its hydro-thermal performance. Steinke et al. [2] evaluated the various enhancement techniques for single phase liquid cooled MCHS and claimed that some methods can match the performance of two phase cooling system. Flow disruptions in microchannels is one of the most widely used enhancement technique by the researchers. Flow disruptions directly influence the fluid mixing and breaking the boundary layer causing flow transition. Flow disruptions can be achieved by inserting pin fins, offset strip fins, in the main channels and ribs in side walls. Chai et al. [3] introduced transverse microchambers where the fluid from all channels is mixed before entering the microchannels again. They introduced rectangular ribs in staggered positions in the microchambers to improve mixing of fluid. They noted three effects of ribs in interrupted microchannels as: interrupted boundary layer, recirculation and mainstream flow separation. They deduced that the heat transfer rate compared to conventional microchannels, increased by 35 percent in interrupted microchannels without ribs and by 63 percent in the interrupted microchannel with ribs. Xie et al. [4] designed five different types of microchannels with bifurcations based on constructal theory and numerically investigated their hydro-thermal performance. They observed that secondary flows are not generated for any type of microchannel even for highest inlet velocity. The overall thermal resistance is lowest for multistage bifurcations with an enhancement factor of 1.78. They concluded that single stage bifurcations having longer length can give better performance if designed properly. Shen et al. [5] used a single vertical rib in the microchannel but varied its distance from outlet end and studied the effect of the position of the vertical rib. They concluded that the introduction of rib the thermal resistance decreases by $27 \%$ and the thermal performance increased by $14 \%$ for rib nearest to the outlet. Lan et al. [6] incorporated dimples and protrusions on the side walls of microchannel and studied the change in flow and thermal performance. Twelve cases were created by varying the span-wise $(\mathrm{P})$ and stream-wise $(\mathrm{S})$ pitch, and combination of dimples and protrusions. For the thermal performance $(\eta)$ for these cases, they noted that: (1) The dimple with protrusion design have better

This paper was recommended for publication in revised form by Regional Editor Jovana Radulovic Government College of Engineering, Karad, India, 415124, Affiliated to Shivaji University, Kolhapur, India ${ }^{*}$ E-mail address: gvinayak2002@gmail.com

Orcid id: 0000-0001-8627-0682; 0000-0002-3681-2284; 0000-0001-7920-779X; 0000-0002-6109-1853

Manuscript Received 16 November 2018, Accepted 21 February 2019 
performance than the dimple and smooth design; (2) The new designs perform better for smaller stream-wise pitch; (3) The staggered designs achieve better results than the non-staggered designs.

Jia et al. [7] introduced cone shaped pin fins microchannels for flow disruptions. Initially, they studied the effects of position of pin-fins by positioning them throughout the length, upstream, downstream and in the middle of microchannel. Later, they optimized the dimensionless parameters of fin such as relative fin diameter, height and spacing between fins. The outcome shows that the introduction of pins in the microchannel improved the heat transfer rate but with a penalty of high pressure drop than the conventional ones. Li et al. [8] computed the effect of dimples and fins placed on microchannel walls on its performance. The new design shows that the temperature of side walls is decreased. The increase of pin diameter and the decrease of stream-wise spacing results in higher Nusselt number ratio.

Duryodhan et al. [9] design consisted of microchannel with converging and diverging channels. The heat transfer phenomenon in such microchannels was studied numerically and experimentally. The test section employed has microchannel of diverging or converging type having $8^{\circ}$ angle and hydraulic diameter of 156 microns. They concluded that due to their unique shape, the new design requires less pumping power compared to conventional parallel microchannels. Comparison between the two new designs shows that the thermal performance of the converging microchannel is higher by $35 \%$ than the diverging one.

Soheil et al. [10] connected two microchannels with transverse microchannels which are of comparatively smaller size. Height and number of transverse channels were the main parameters in increase in performance. They concluded that transverse microchannels resulted in additional entrance effects which helped in increase in Nusselt number and pressure drop.

Li et al. [11] introduced ribs and triangular cavities in microchannel walls and studied their hydro-thermal performance characteristics. The thermal performance of the new design was analyzed by the method of minimization of entropy generation. The new design achieved the enhancement factor of 1.6 for a heat flux of 100 Watt per sq.cm and cooled by water flowing with Reynolds number of 500. Kuppuswamy et al. [12] introduced secondary flows by having slanted passages having alternate directions in the wall separating the neighboring channels. They reported that the overall performance of enhanced microchannel improved by $146 \%$ and thermal resistance decreased by $77 \%$ and was accompanied by $6 \%$ pressure drop compared to conventional microchannel. Lee et al. [13] employed small channels placed obliquely to connect the parallel (primary) channels. The presence of oblique channel results in diversion of a small part of the flow from one primary channel into neighboring primary channel. The continuous wall of primary channel is broken by the oblique channel which results in breaking of the thermal and hydrodynamic boundary layer, and increase in fluid mixing. They reported that the average Nusselt number of such fins increased by $103 \%$. Also the maximum temperature rise was less by $12.6^{\circ} \mathrm{C}$. Use of combination of secondary channels and ribs was employed by Ghani et al. [14]. Ribs are used to force the fluid to flow into the secondary channels. Thermal performance of this hybrid design was compared with conventional rectangular channels, alternating secondary channels and channels with ribs. The hybrid design increased the performance by a factor of 1.98 .

Yadav et al. [15] numerically studied the performance of microchannel having pins concentrated at the inlet region, near the outlet region and uniformly dispersed in the entire channel. The performance was studied for heat flux of hundred and two hundred watts per sq. $\mathrm{cm}$ and subjected to flow rates corresponding to Reynolds number ranging from 400 to 1200 . They observed that in the microchannels with pin fins, the bottom wall temperature is reduced significantly than conventional microchannel. The heat transfer performance of microchannels having pins at the inlet region is better than other cases for lower Reynolds number, while the complete finned microchannel performs better for higher Reynolds number. Zunaid et al. [16] studied the effect of semi cylindrical projections on pressure drop and heat transfer characteristics. They compared the results with conventional rectangular microchannel heat sink and found that the semi cylindrical projections help increase the heat transfer but with increase in pressure drop penalty. Belhadj et al. [17] employed cylindrical grooves and triangular cavities to created periodic expansion constriction cross section and studied its effect on thermo-hydraulic performance. They concluded that the Nusselt number maximum increased by $36 \%$ whereas the pressure drop increased by $44 \%$. Table 1 lists the research work done in the enhanced techniques of MCHS. 
Journal of Thermal Engineering, Research Article, Vol. 6, No. 5, pp. 677-696, October, 2020

Table 1. List of MCHS performance enhancement methods investigated by researchers

\begin{tabular}{|c|c|c|c|c|c|c|c|c|}
\hline $\begin{array}{l}\text { Sr. } \\
\text { No. }\end{array}$ & Author & Year & $\begin{array}{l}\text { Num/ } \\
\text { Exp }\end{array}$ & $\begin{array}{c}\text { Enhancement } \\
\text { technique }\end{array}$ & $\begin{array}{c}\text { MC } \\
\text { dimensions } \\
\text { (microns) }\end{array}$ & $\begin{array}{c}\text { Heat } \\
\text { flux } \\
\text { range } \\
(\mathrm{W} / \\
\left.\mathrm{cm}^{2}\right)\end{array}$ & $\begin{array}{l}\text { Flow } \\
\text { rates }\end{array}$ & $\begin{array}{c}\text { Enhance } \\
\text { ment } \\
\text { parameter } \\
(\eta)\end{array}$ \\
\hline 1 & $\begin{array}{l}\text { Lei Chai } \\
\text { et al. }\end{array}$ & 2013 & Num & $\begin{array}{l}\text { Rectangular } \\
\text { ribs in } \\
\text { transverse } \\
\text { microchambers }\end{array}$ & $\begin{array}{c}\mathrm{W}=100 ; \\
\mathrm{H}=200 ; \\
\text { Wall=250 }\end{array}$ & 122 & $\begin{array}{l}\mathrm{Re}= \\
200 \text { to } \\
700\end{array}$ & $\begin{array}{c}\eta=1.26 \text { to } \\
1.35\end{array}$ \\
\hline 2 & Xie et al. & 2014 & Num & Plates & $\begin{array}{l}W=315 \\
H=400\end{array}$ & 24.5 & $\begin{array}{c}\mathrm{Re}= \\
230 \text { to } \\
560\end{array}$ & $\mathrm{R} / \mathrm{R}_{0}=1.78$ \\
\hline 3 & $\begin{array}{l}\text { Shen et } \\
\text { al. }\end{array}$ & 2018 & Num & $\begin{array}{c}\text { Vertical } \\
\text { bifurcations }\end{array}$ & $\begin{array}{l}\mathrm{W}=298 ; \\
\mathrm{H}=400\end{array}$ & 100 & $\begin{array}{c}\mathrm{Re}= \\
100 \text { to } \\
1000\end{array}$ & 1.14 \\
\hline 4 & Lan et al. & 2012 & Num & Dimples & $\begin{array}{l}W=50 \\
H=200\end{array}$ & 50 & $\begin{array}{c}\mathrm{Re}= \\
100 \text { to } \\
900\end{array}$ & $\begin{array}{c}\eta=1.12 \text { to } \\
4.77\end{array}$ \\
\hline 5 & Jia et al. & 2018 & Num & $\begin{array}{l}\text { Cone shaped } \\
\text { pin fins }\end{array}$ & $\begin{array}{l}W=200 \\
H=200\end{array}$ & 100 & $\begin{array}{c}\mathrm{Re}= \\
150 \text { to } \\
640\end{array}$ & $\eta=1.5$ \\
\hline 6 & Li et al. & 2018 & Num & Dimple and fin & $\begin{array}{l}\mathrm{W}=50 ; \\
\mathrm{H}=200\end{array}$ & 50 & $\begin{array}{l}\mathrm{Re}=50 \\
\text { to } 300\end{array}$ & 1.9 \\
\hline 7 & $\begin{array}{l}\text { Vijay D } \\
\text { etal. }\end{array}$ & 2015 & $\begin{array}{c}\text { Num+ } \\
\text { Exp }\end{array}$ & $\begin{array}{l}\text { Converging } \\
\text { Diverging } \\
\text { Channels }\end{array}$ & $\begin{array}{l}\mathrm{W} 1=252 ; \\
\mathrm{W} 2=3052\end{array}$ & $\begin{array}{l}0.3 \text { to } \\
9.5\end{array}$ & $\begin{array}{c}\operatorname{Re}=80 \\
\text { to } 180\end{array}$ & $\mathrm{~h} / \mathrm{h}_{0}=1.35$ \\
\hline 8 & $\begin{array}{c}\text { Soheil et } \\
\text { al. }\end{array}$ & 2018 & Num & Transverse MC & $\begin{array}{l}\mathrm{W}=370 ; \\
\mathrm{H}=425\end{array}$ & 80 & $\begin{array}{c}\mathrm{Re}= \\
200 \text { to } \\
1000\end{array}$ & 2.3 \\
\hline 9 & Li et al. & 2016 & Num & $\begin{array}{l}\text { Triangular } \\
\text { cavity \& rect } \\
\text { ribs }\end{array}$ & $\begin{array}{l}W=200 ; \\
H=200\end{array}$ & 100 & $\begin{array}{c}\mathrm{Re}= \\
160 \text { to } \\
640\end{array}$ & $\eta=1.55$ \\
\hline 10 & $\begin{array}{c}\text { Kuppus } \\
\text { wamy et } \\
\text { al. }\end{array}$ & 2014 & Num & Sec flows & $\begin{array}{l}\mathrm{W}=300 ; \\
\mathrm{H}=300\end{array}$ & 100 & $\begin{array}{c}\mathrm{m}= \\
0.001 \\
\mathrm{~kg} / \mathrm{s}\end{array}$ & 1.46 \\
\hline 11 & Lee et al. & 2012 & $\begin{array}{c}\text { Num+ } \\
\text { Exp }\end{array}$ & Oblique fins & $\begin{array}{c}W 1=500 ; \\
W 2=300 ; \\
H=1500\end{array}$ & 100 & $\begin{array}{c}\mathrm{Re}= \\
325 \text { to } \\
780\end{array}$ & $\eta=1.6$ \\
\hline 12 & $\begin{array}{c}\text { Ghani et } \\
\text { al. }\end{array}$ & 2017 & Num & $\begin{array}{l}\text { Ribs n sec } \\
\text { channels }\end{array}$ & $\begin{array}{l}\mathrm{W}=300 \\
\mathrm{H}=300\end{array}$ & 100 & $\begin{array}{c}\mathrm{Re}= \\
100 \text { to } \\
800\end{array}$ & 1.98 \\
\hline 13 & $\begin{array}{c}\text { Yadav et } \\
\text { al. }\end{array}$ & 2016 & Num & Pinfins in MC & $\begin{array}{c}\mathrm{W}=231 ; \mathrm{H}=71 \\
3\end{array}$ & $\begin{array}{l}100 \\
200\end{array}$ & $\begin{array}{c}\mathrm{Re}= \\
400 \text { to } \\
1200\end{array}$ & $\eta=1.73$ \\
\hline
\end{tabular}


Secondary flows can be observed in nature like in flow in rivers, sap flow in trees, leaf venation, blood circulation in humans etc. Carlos et al. [18] proposed secondary flows by branching as observed in nature in the microchannel to obtain the uniform temperature profile. Six models were designed on two laws of nature viz. Allometric and Biomimetic law. Unfortunately, the temperature profile was not as expected. A non-uniform temperature profile was obtained where the mid region showed higher temperature. The results also showed larger temperature gradients than the conventional method. Wang et al. [19] also studied the secondary flows in microchannels. They designed microchannels based on tree like branching, leaf venation of symmetric and asymmetric networks. The results showed that leaf venation pattern has better performance.

Careful study of the literature above indicates that there is lot of scope in the enhancement of performance of MCHS. In this paper, we employ small channels to connect the main channels to create secondary flows and increase the fluid mixing and heat transfer. The conventional parallel microchannels henceforth called the primary channels are connected by a set of secondary channels creating a leaf like pattern. The flow network thus created by primary and secondary channels results in a flow which has boundary layers always at developing state in the microchannel resulting in a very high heat transfer rate along the channel length, which helps in reducing the temperature gradient $(\Delta \mathrm{T} / \Delta \mathrm{Z})$ along the length of channel and lowering the surface temperature $\left(\mathrm{T}_{\max }\right)$.

\section{METHDOLOGY}

\section{Enhanced MCHS Design}

The enhanced microchannel configuration is as shown in Figure 1. The proposed design is based on pinnate type leaf venation pattern. In this type of pattern, the primary vein has a number of branches on its either side called secondary veins which further branch into smaller size veins. The proposed design has two channels viz. primary channel and secondary channel. The primary channels are parallel to each other while the secondary channels are channels of smaller width connecting the primary channel at an angle (Figure $1 \mathrm{a}$ ). The design consists of a set of three primary channels of length $25 \mathrm{~mm}$ connected together by a number of secondary channels depicting a leaf venation pattern. Each set has three inlets and two outlets as the central primary channel outlet is blocked which helps the coolant to flow into the secondary channels (Figure 1b). Eight such sets of primary-secondary channels are used to form enhanced MCHS having a footprint of $25 \mathrm{~mm}$ x $25 \mathrm{~mm}$ (Figure 2). The key characteristics of conventional and enhanced MCHS are tabulated in Table 2.

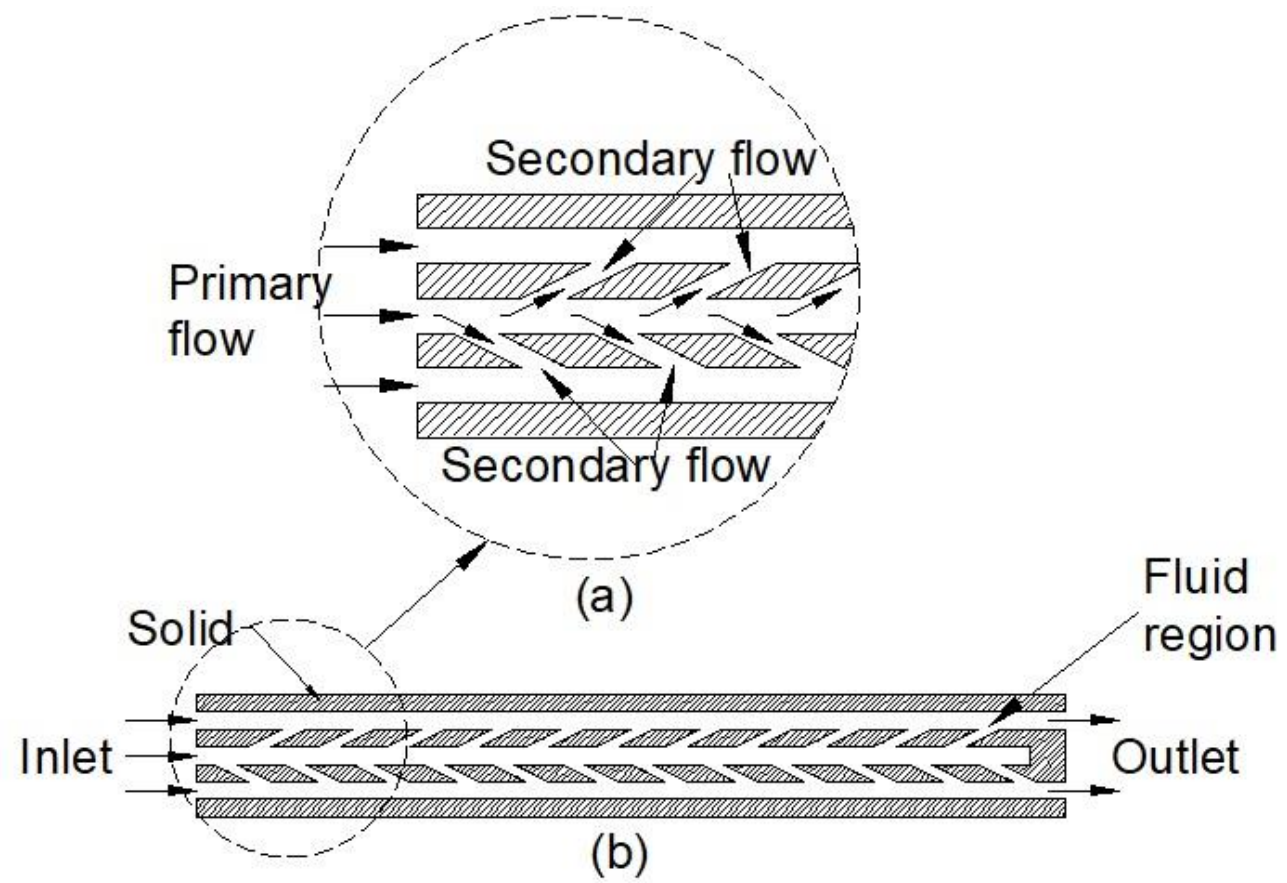

Figure 1. Enhanced MCHS (a) flow definition and (b) computational domain 


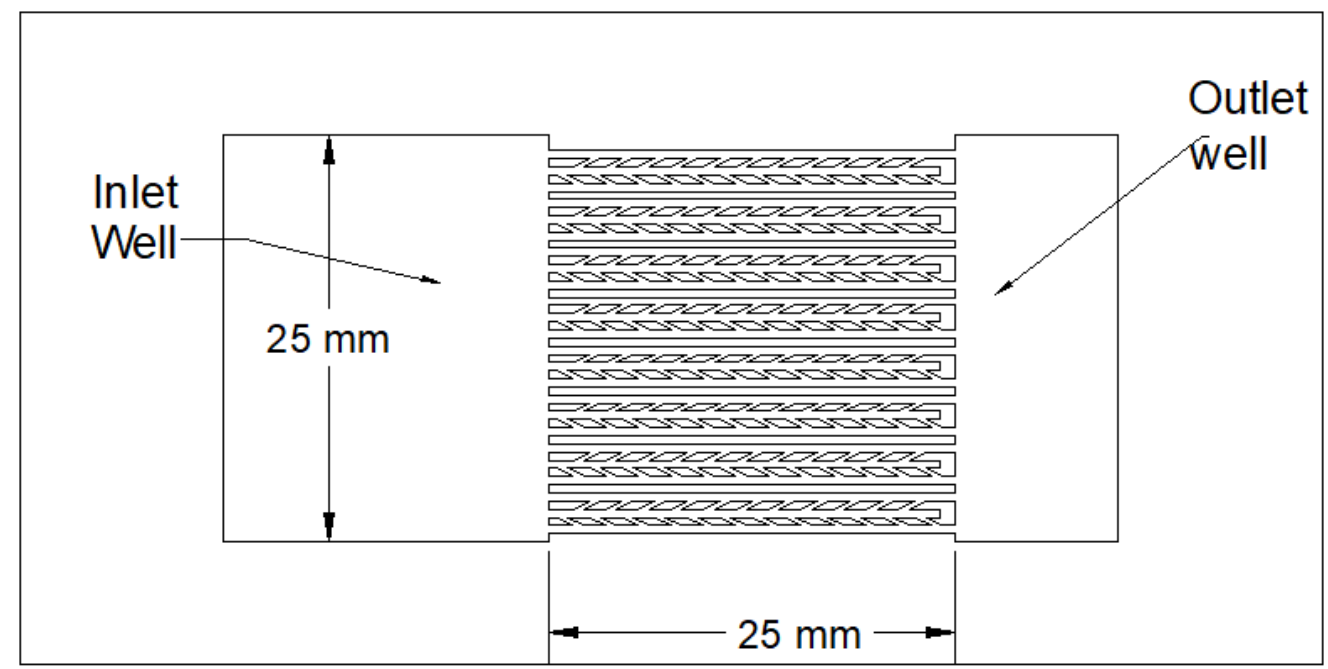

Figure 2. Enhanced MCHS design

Table 2. Dimensions of MCHS

\begin{tabular}{|c|c|c|}
\hline Characteristics & $\begin{array}{c}\text { Conventional } \\
\text { MCHS }\end{array}$ & $\begin{array}{c}\text { Enhanced } \\
\text { MCHS }\end{array}$ \\
\hline Material & Copper & Copper \\
\hline Footprint $\mathrm{L} \times \mathrm{W}(\mathrm{mm})$ & $25 \times 25$ & $25 \times 25$ \\
\hline Primary channel width $\mathrm{W}_{\mathrm{c}}(\mu \mathrm{m})$ & 500 & 500 \\
\hline Wall width $\mathrm{W}_{\mathrm{w}}(\mu \mathrm{m})$ & 500 & 500 \\
\hline Channel height $\mathrm{H}_{\mathrm{c}}(\mu \mathrm{m})$ & 900 & 900 \\
\hline Aspect ratio $\left(\mathrm{H}_{\mathrm{c}} / \mathrm{W}_{\mathrm{c}}\right)$ & 1.8 & 1.8 \\
\hline Number of fin rows & 24 & 24 \\
\hline Secondary channel width $\mathrm{W}_{\mathrm{s}}(\mu \mathrm{m})$ & -- & 300 \\
\hline Secondary channel angle $(\mathrm{deg})$ & -- & 27 \\
\hline
\end{tabular}

\section{Simulation Model}

Numerical analysis of conventional and enhanced MCHS is done using ANSYS FLUENT WORKBENCH 18.1(Academic version). For conventional MCHS, a single channel with half width of side wall is used as computational domain (Figure 3a). As we can see from the Figure 2, the entire enhanced MCHS is made of eight sets. If the effects at the edges are neglected, the computational domain of a single set consisting of three primary channels and interconnecting secondary channels sufficiently represents the enhanced MCHS geometry (Figure 3b). Hexahedral elements are used for meshing of computational domain of conventional MCHS, while tetrahedral elements are used for enhanced MCHS. The simulations are performed by numerically solving the governing equations. The governing equations are as follows: 
Continuity equation:

$$
\nabla \cdot(\rho \vec{v})=0
$$

Momentum equation:

$$
\nabla \cdot(\rho \vec{v} \vec{v})=-\nabla P+\nabla \cdot(\mu \nabla \vec{v})
$$

Energy equation for liquid:

$$
\nabla \cdot(\rho \vec{v}(C p T)=\nabla \cdot(k \nabla T)
$$

Energy equation for solid:

$$
\nabla \cdot(k \nabla T)=0
$$

The following assumptions are made for the simulation.

- Steady state

- Laminar flow

- Heat transfer by radiation and natural convection is negligible.

- Temperature dependent fluid properties

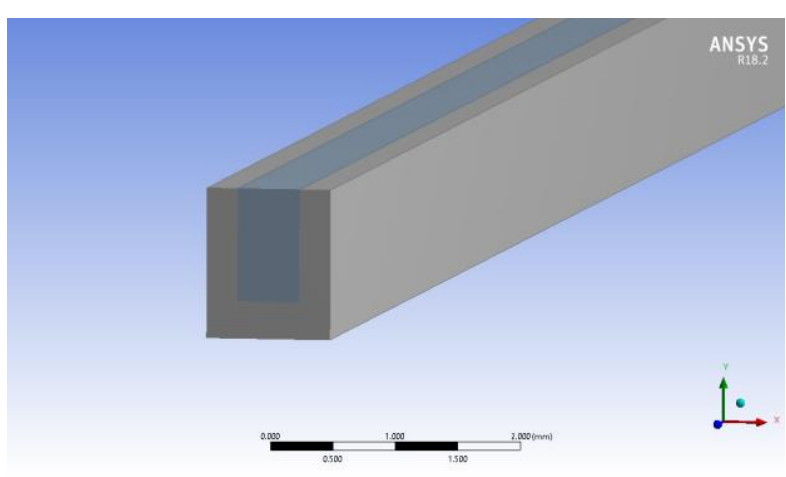

(a)

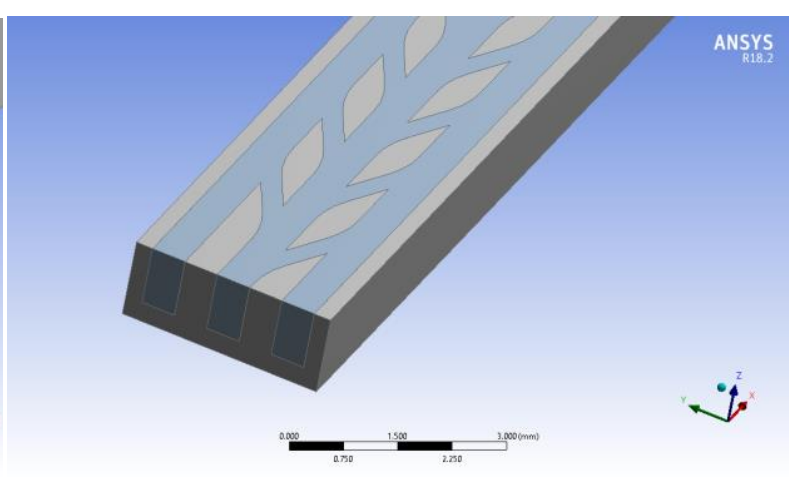

(b)

Figure 3. Computational model of (a) conventional MCHS (b) enhanced MCHS

The three-dimensional, double precision, solver is used with SIMPLE scheme for pressure-velocity coupling. For the spatial discretization scheme, second order is used for the pressure equation while second order upwind scheme is used for both momentum and energy equations. In solution controls, the under-relaxation factors used are: 0.5 for pressure and for momentum, and 1.0 for density, momentum and energy. In the monitors, the residual convergence criterion of $10^{-6}$ is set for all equations. Copper with constant thermal conductivity of $387.6 \mathrm{~W} / \mathrm{mK}$ is chosen as the solid material. Water with temperature dependent properties is chosen as the fluid material.

The fluid properties of water are evaluated at the mean fluid temperature $(\mathrm{T})$ with reference to [20] by the following equations: 
Density:

$$
\rho=\frac{a_{0}+a_{1} T+a_{2} T^{2}+a_{3} T^{3}+a_{4} T^{4}+a_{5} T^{5}}{1+b T}
$$

where, $\mathrm{a}_{0}=999.8396, \mathrm{a}_{1}=18.22494, \mathrm{a}_{2}=-7.92221 \times 10^{-3}, \mathrm{a}_{3}=-5.544485 \times 10^{-5}, \mathrm{a}_{4}=1.49756 \times 10^{-7}, \mathrm{a}_{5}=-3.93295 \mathrm{x}$ $10^{-10}, \mathrm{~b}=-1.81597 \times 10^{-2}$ and $\mathrm{T}$ is in degree Celsius.

Specific heat capacity:

$$
C p=8958.9-40.535 * T+0.112343 * T^{2}-1.0138 * 10^{-3} * T^{3}
$$

Thermal Conductivity:

$$
K f=-0.58166+6.3555 * 10^{-3} * T-7.9643 * 10^{-6} * T^{2}
$$

Dynamic Viscosity:

$$
\mu=2.414 * 10^{-5} \times 10^{\left(\frac{247.8}{T-140}\right)}
$$

For the equations 6, 7, and 8, the temperature, $\mathrm{T}$ is in Kelvin (K).

\section{Boundary Conditions}

The inlet flow of microchannel was considered to be hydro-dynamically developed but thermally developing one as per the findings by Lee et al. [21]. First, at the inlet section, constant velocity corresponding to the flow rate is applied and the analysis is performed without heat transfer. The velocity profile obtained at the outlet is a hydrodynamically developed one. The extracted velocity profile from the outlet is then assigned to the inlet with required heat flux boundary conditions. The temperature assigned to the inlet fluid is $305 \mathrm{~K}$. Heat flux ranging from of $65 \mathrm{Watt}$ per sq. $\mathrm{cm}$ to 200 Watt per sq.cm was applied at the base of the solid region; the microchannel top wall surface is adiabatic. Pressure outlet is applied at the outlet.

\section{GRID INDEPENDENCE}

To ensure the results are independent of grid size, the number of elements of conventional MCHS is varied from 720 thousand to 900 thousand and the relative error of fluid temperature is calculated. The relative error of fluid temperature for the increase in number of elements is 0.04 percent, hence the grid with 0.72 million elements is selected for further simulations.

\section{Data Reduction}

The Reynolds number is given by the expression:

$$
R e=\frac{\rho \mathrm{U}_{m} D_{h}}{\mu}
$$

where $\rho, U_{m}, \mu$ are fluid density, mean velocity, and dynamic viscosity. $D_{h}$ is the hydraulic diameter of the channel and is given by

$$
D h=\frac{2 H_{c} W_{c}}{\left(H_{c}+W_{c}\right)}
$$


Journal of Thermal Engineering, Research Article, Vol. 6, No. 5, pp. 677-696, October, 2020

The average heat transfer coefficient is given by

$$
h_{\text {ave }}=\frac{q_{w} A_{\text {bottom }}}{A_{\text {con }}\left(T_{s}-T_{f}\right)}
$$

where $\mathrm{q}_{\mathrm{w}}$ is the heat flux applied to the bottom of MCHS, $\mathrm{A}_{\text {bottom }}$ is the bottom surface area, $\mathrm{A}_{\text {con }}$ is the convection heat transfer area, $T_{s}, T_{f}$ are the average surface temperature and fluid mean temperature respectively.

The average Nusselt number is obtained by

$$
N u_{\text {ave }}=\frac{h_{\text {ave } D_{h}}}{k_{f}}
$$

Energy balance gives the temperature difference between inlet section and outlet section:

$$
T_{o}-T_{i}=\frac{q_{w} A_{\text {bottom }}}{\rho A_{\text {in }} U_{m} C_{p}}
$$

The Poiseuille number (Po) is calculated ref. (19) as

$$
P_{o}=24\left(1-1.3553 \delta+1.9467 \delta^{2}-1.7012 \delta^{3}+0.9564 \delta^{4}-0.2537 \delta^{5}\right)
$$

where, $\delta$ is the aspect ratio, a ratio of channel width by channel height

$$
\delta=\frac{W_{c}}{H_{c}}
$$

The apparent friction factor as per [22] is given by

$$
\mathrm{f}_{\mathrm{app}}=\mathrm{f}+\frac{\alpha(x) D_{h}}{L}
$$

where $\alpha(\mathrm{x})=0.6796+1.2197 \delta+3.3089 \delta^{2}-9.5921 \delta^{3}+8.9089 \delta^{4}-2.9959 \delta^{5}$

Pressure drop is obtained from eq. (14) to (17) as

$$
\Delta p=\frac{2(f R e) \mu U_{m} L}{D_{h}^{2}}+\frac{\alpha(x) \rho U_{m}^{2}}{2}
$$

Thermal resistance $(\mathrm{R})$ is calculated as

$$
R=\frac{\Delta T_{R}}{q}
$$

where, $\Delta T_{R}$ is the rise in temperature of the surface above inlet temperature and $\mathrm{q}$ is the dissipated power.

The overall enhancement factor ref [23] is a function of Nusselt number ratio and friction factor ratio given by

$$
\eta=\frac{N u / N u_{0}}{\left(\frac{f}{f_{0}}\right)^{0.333}}
$$




\section{RESULTS AND DISCUSSION Validation}

To ascertain the accuracy and reliability of the numerical simulation, few parameters from the simulation are compared with theoretical ones. The pressure drop and difference in inlet outlet temperature for the conventional microchannel are considered here. The simulation results of conventional MCHS are compared with the theoretical values of pressure drop (given by equation 18) and fluid temperature difference at inlet and outlet sections (given by equation 13). The correlations by Shah and London [24] and Steinke and Kandlikar [22] have been used for the theoretical values. Figure 4 show that the numerical simulation results have less than 10 percent variation with the theoretical data for all Reynolds number.

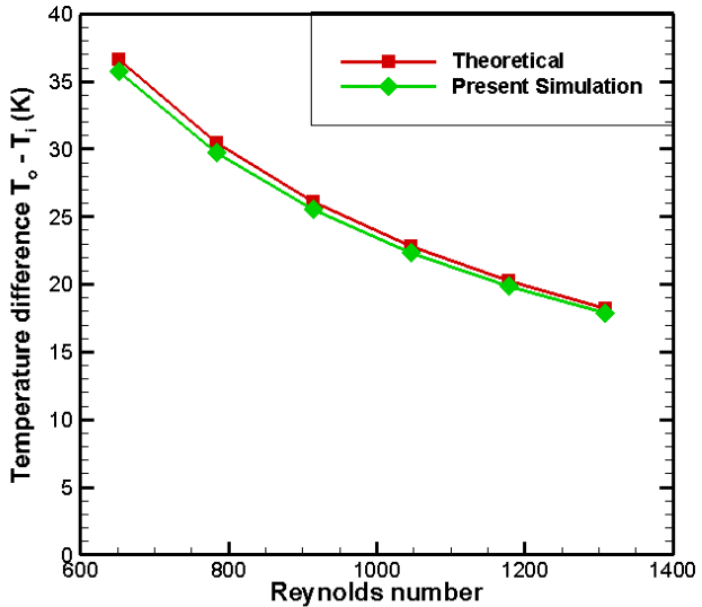

(a)

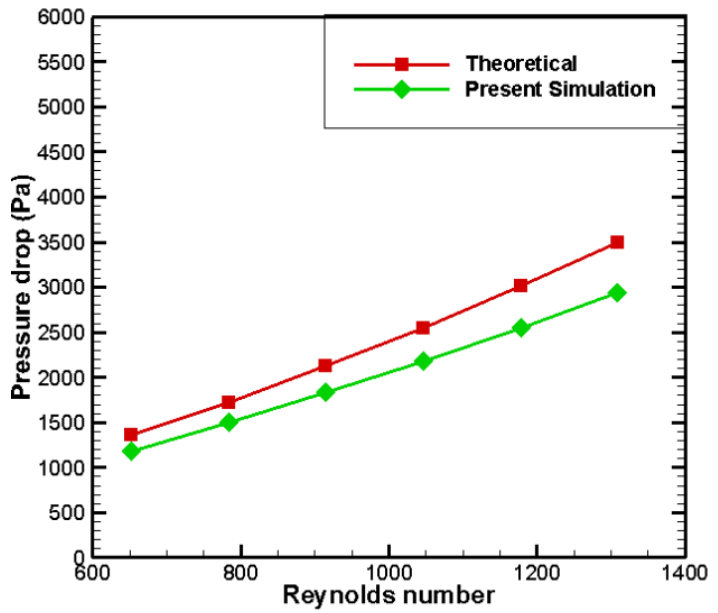

(b)

Figure 4. Comparison of theoretical and present simulation values of (a) Fluid temperature difference at inlet and outlet sections (b) Pressure drop for various Reynolds numbers

\section{Fluid Flow And Heat Transfer Characteristics Of Microchannel}

To understand the effect of secondary channels on the fluid flow, streamlines, velocity and temperature contours are plotted at mid-region in conventional and enhanced MCHS at Reynolds number of 652 and subjected to heat flux of 200 Watt per sq.cm (Figure 5 to 10). The streamlines of conventional MCHS (Figure 5) describe a fixed flow pattern while a continuously varying flow pattern is obtained in enhanced MCHS (Figure 6). The streamlines in enhanced MCHS near the primary channel walls are interrupted by the inlet of secondary channels as some amount of fluid flows into the secondary channels. The streamlines again become continuous after the inlet region only to be disturbed again by the next secondary channel. The array of secondary channels on either side of central primary channel causes some part of the flow to be diverted into the adjacent primary channel via these secondary channels. This results in the flow in all three primary channels to be constantly in a developing state. The streamlines in the secondary channels indicate that the flow passes smoothly through the secondary channel but meets resistance at the exit from the primary flow flowing in the adjacent primary channel. This causes the flow to change its direction slightly and eventually mix with primary flow. Enhanced MCHS design causes more amount of coolant to come in contact with the surface area. All these factors results in more amount of heat removal by the MCHS.

Velocity distribution in both MCHS is shown in Figure 7 and 8. In conventional MCHS maximum velocity is concentrated in the central region of the channel and it does not change along the channel length. In enhanced MCHS, the velocity varies along the length as well as across the cross section of the channel. Velocity in the central channel varies from maximum at inlet to zero at the blocked end, while in the neighboring channels it keeps increasing along the length. In enhanced MCHS, the secondary channels have least velocity. 
Journal of Thermal Engineering, Research Article, Vol. 6, No. 5, pp. 677-696, October, 2020

Velocity

$\left[m s^{\wedge}-1\right]$
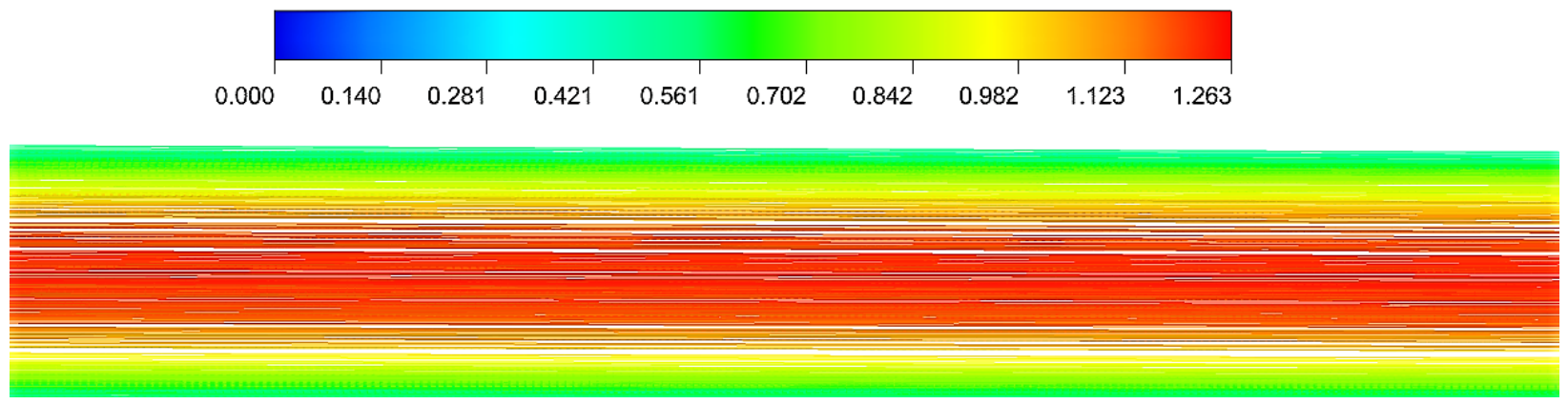

Figure 5. Velocity streamlines for conventional MCHS in the mid region $(\mathrm{Hc}=450 \mu \mathrm{m})$

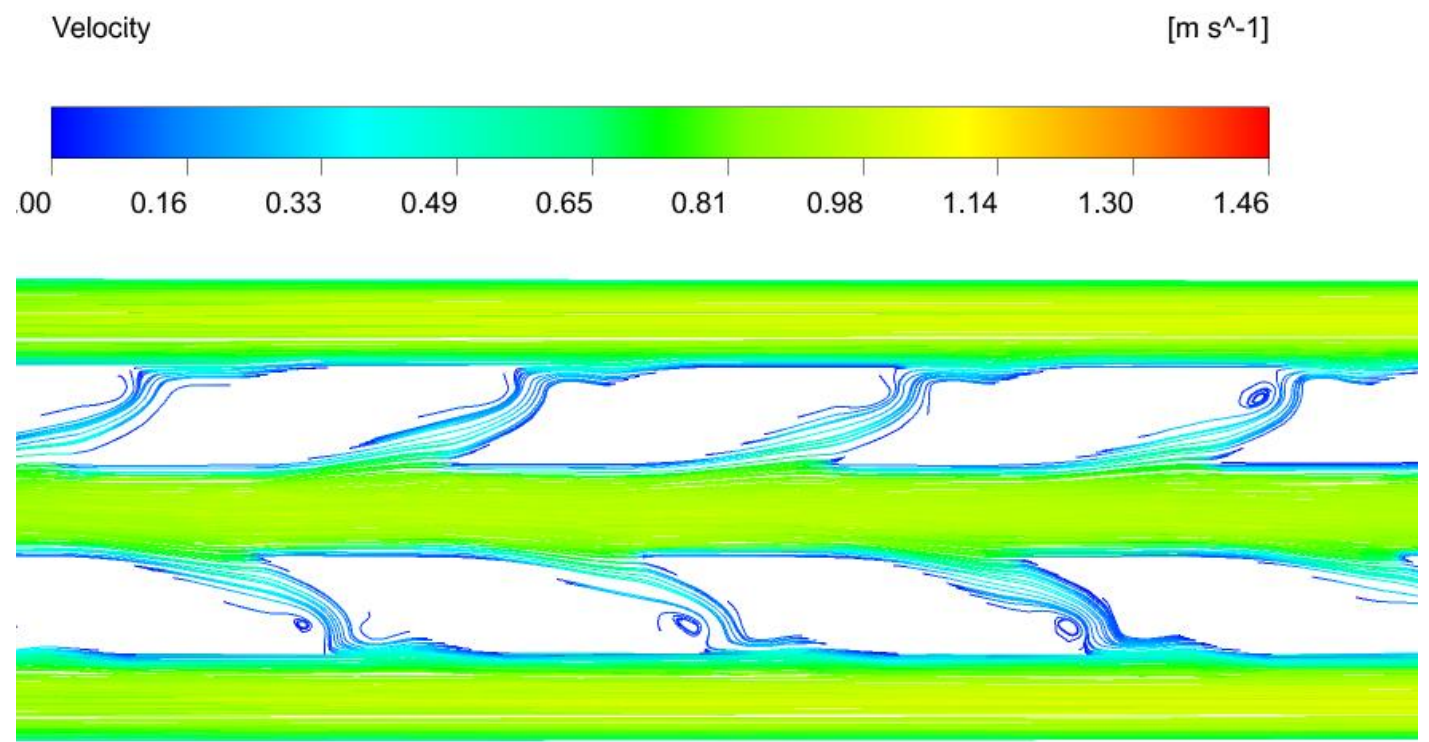

Figure 6. Velocity streamlines for enhanced MCHS in the mid region $\left(H_{c}=450 \mu \mathrm{m}\right)$

Velocity

$\left[\mathrm{m} \mathrm{s}^{\wedge}-1\right]$

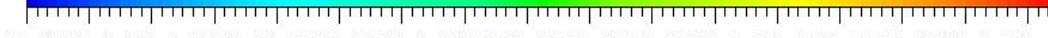

$\begin{array}{lllllllllllllllll}0.17 & 0.23 & 0.30 & 0.36 & 0.43 & 0.50 & 0.56 & 0.63 & 0.70 & 0.76 & 0.83 & 0.90 & 0.96 & 1.03 & 1.10 & 1.16 & 1.23\end{array}$

Figure 7. Velocity contour for conventional MCHS in the mid region $\left(\mathrm{H}_{\mathrm{c}}=450 \mu \mathrm{m}\right)$ 
Journal of Thermal Engineering, Research Article, Vol. 6, No. 5, pp. 677-696, October, 2020

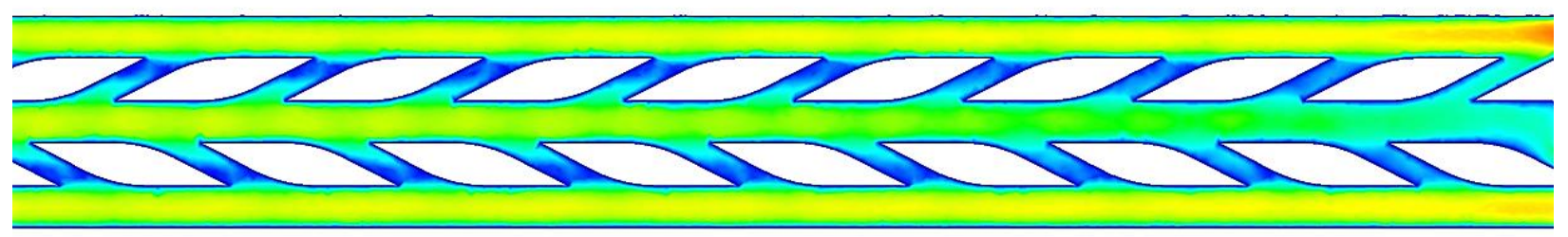

Figure 8. Velocity contour for enhanced MCHS in the mid region $\left(\mathrm{H}_{\mathrm{c}}=450 \mu \mathrm{m}\right)$

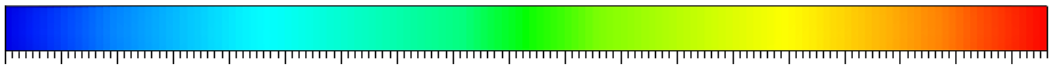

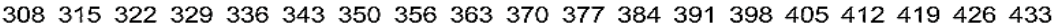

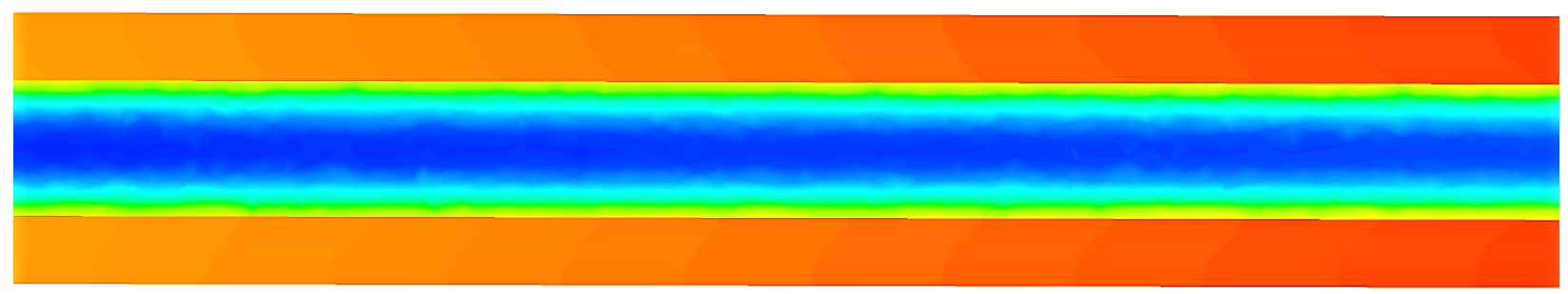

Figure 9. Temperature contour for conventional MCHS in the mid region $\left(\mathrm{H}_{\mathrm{c}}=450 \mu \mathrm{m}\right)$

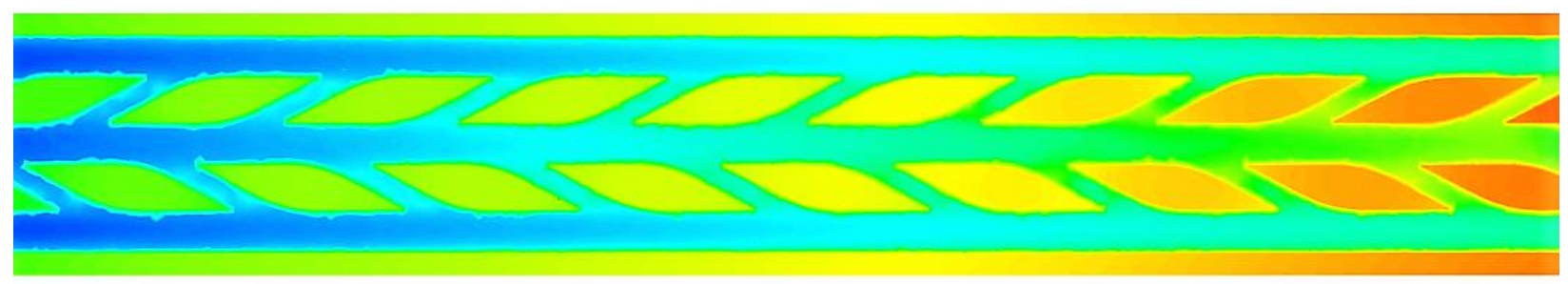

Figure 10. Temperature contour for enhanced MCHS in the mid region $\left(\mathrm{H}_{\mathrm{c}}=450 \mu \mathrm{m}\right)$ 


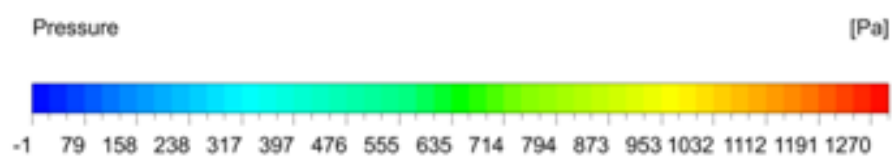

(a)

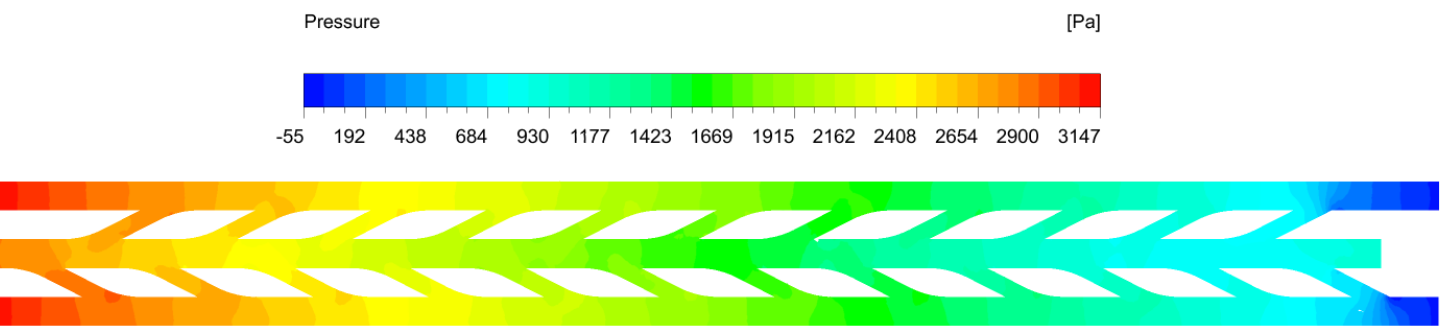

(b)

Figure 11. Pressure variation for (a) conventional and (b) enhanced MCHS in the mid region $\left(\mathrm{H}_{\mathrm{c}}=450 \mu \mathrm{m}\right)$

Figure 9, 10 shows the temperature contours for conventional and enhanced MCHS. In conventional MCHS, maximum temperature $440 \mathrm{~K}$ is visible on the solid surface at the outlet region while the minimum temperature is at the central region of the channel. In enhanced MCHS, maximum temperature of $380 \mathrm{~K}$ is visible at the outlet region of central primary channel while the minimum temperature is at the inlet region. Thus a difference of nearly $60 \mathrm{~K}$ is present between the MCHS.

Pressure drop in both MCHS is shown in Figure 11 a) and b). For both MCHS the pressure reduces along the length mainly due to frictional losses. Pressure drop in enhanced MCHS is more compared to conventional MCHS primarily due to the closing of outlet of central main channel. Presence of secondary channels helps in recovering some of the pressure loss. Compared to similar designs proposed by earlier researchers, such as microchannel with secondary channels (MC-SOC) in alternating directions mentioned in Ghani et al. (13), the pressure drop in enhanced MCHS (3350 Pascal compared to 45000 Pascal) is much lower.

To analyze the effect of closing of central channel outlet, a separate MCHS with three outlets was created and subjected to same boundary conditions. Figure 12 and 13 show the comparison of performance of enhanced MCHS with three and two outlets subjected to heat flux of 200 Watt per sq.cm. Streamlines are plotted for three outlets in Figure 12. a) and for two outlets in Figure 12. b). Due to the removal of the blocked outlet of central channel (enhanced MCHS with three outlets), the fluid flows along the least resistance path and hence does not enter in most of the secondary channels, while the reverse is true for the enhanced MCHS with two outlets. Comparison of temperature at the mid-plane for both enhanced MCHS is shown in Figure 13. In enhanced MCHS with three outlets, the fluid temperature suggests that it removes very little heat from the channel hence increasing the temperature in the outlet region. A temperature difference of 49 Kelvin is observed between the two designs, which reinforce the validity of closing of outlet of central channel of enhanced MCHS. 
Journal of Thermal Engineering, Research Article, Vol. 6, No. 5, pp. 677-696, October, 2020
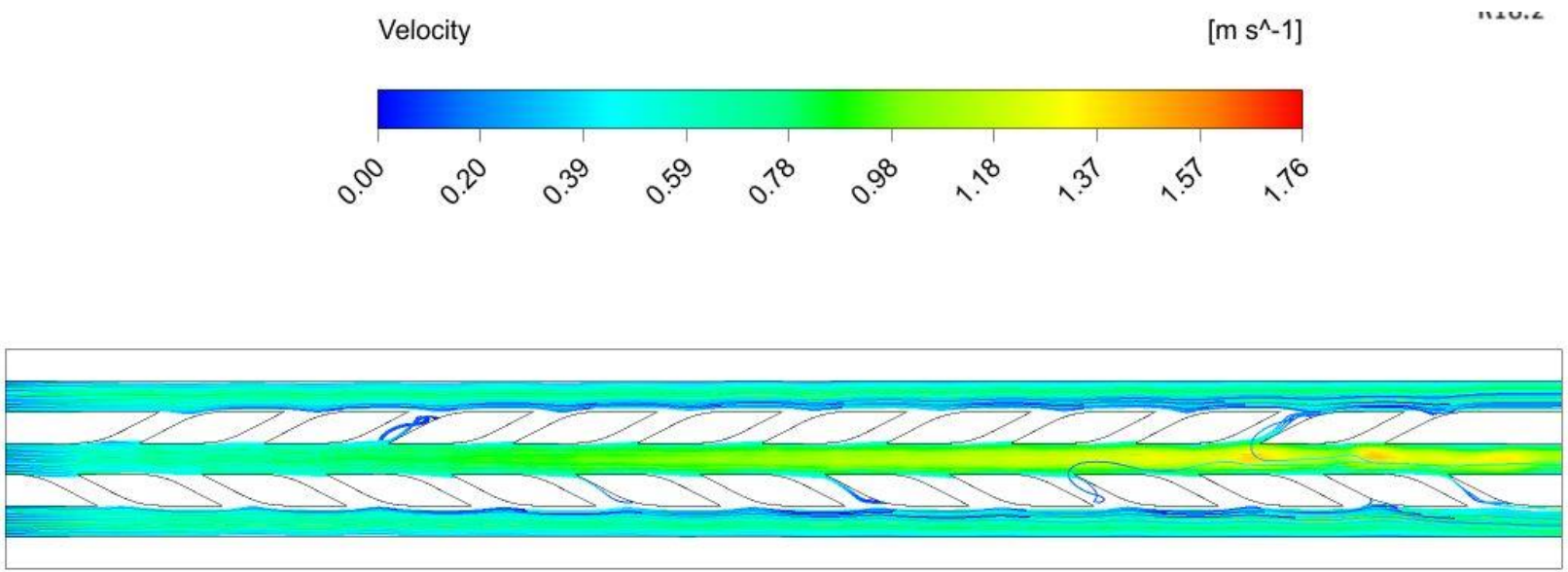

(a)
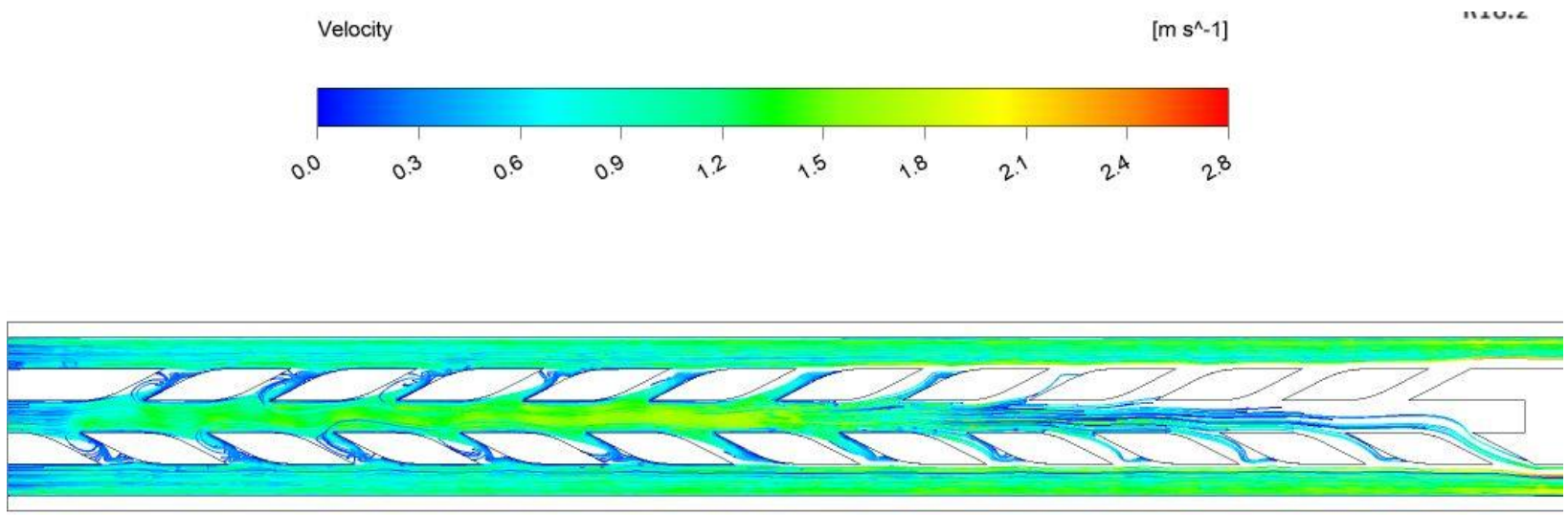

(b)

Figure 12. Streamlines for enhanced MCHS with (a) three outlets and (b) two outlets

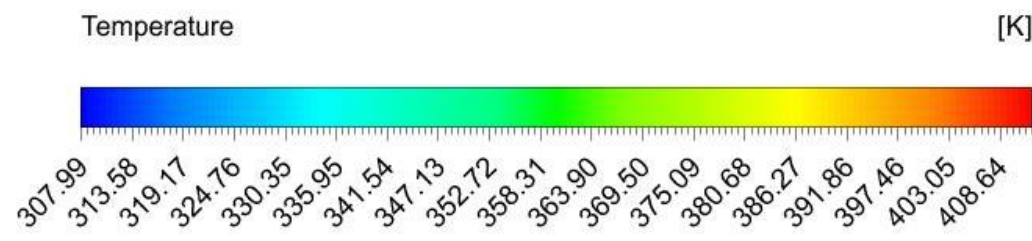

(a) 


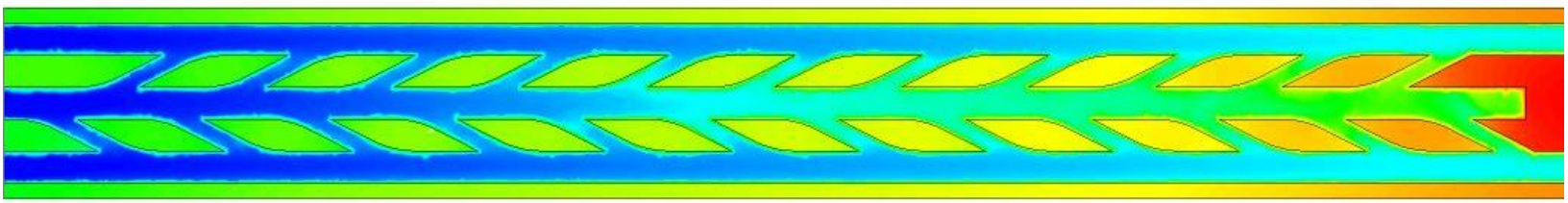

(b)

Figure 13. Temperature contours at midplane for enhanced MCHS with (a) three outlets and (b) two outlets

\section{Performance Analysis}

Performance of conventional and enhanced MCHS is compared for heat flux of 100 Watt per sq.cm and 200 Watt per sq.cm. Figure 14 shows the effect of Reynolds number on Nusselt number. As expected, for both conventional and enhanced MCHS, there is rise in Nusselt number with increase in Reynolds number. For enhanced MCHS, Nusselt number attained is much higher than for conventional MCHS for both heat flux conditions. The heat removed by enhanced MCHS is nearly two times than the conventional MCHS. Presence of secondary channels results in additional pressure drop as seen in Figure $15 \mathrm{a}$ ) and b). Pressure drop increases with increase in Reynolds number for both MCHS, but it increases rapidly for enhanced MCHS. The pressure drop in enhanced MCHS is nearly three times higher than conventional MCHS.

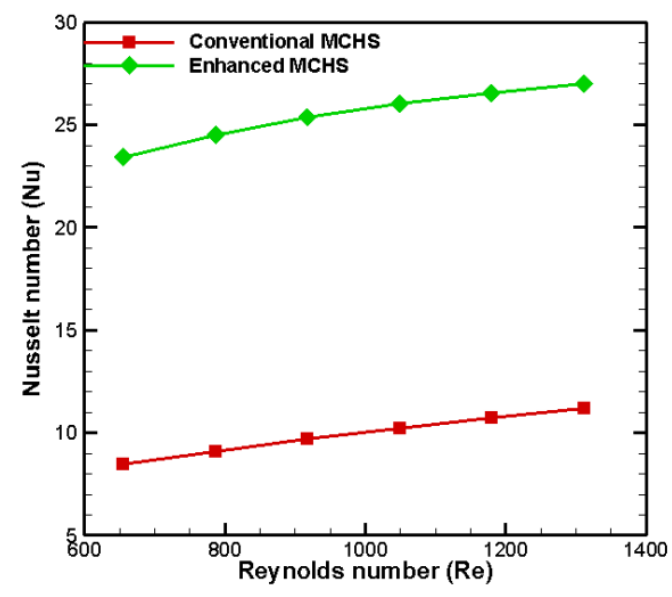

(a)

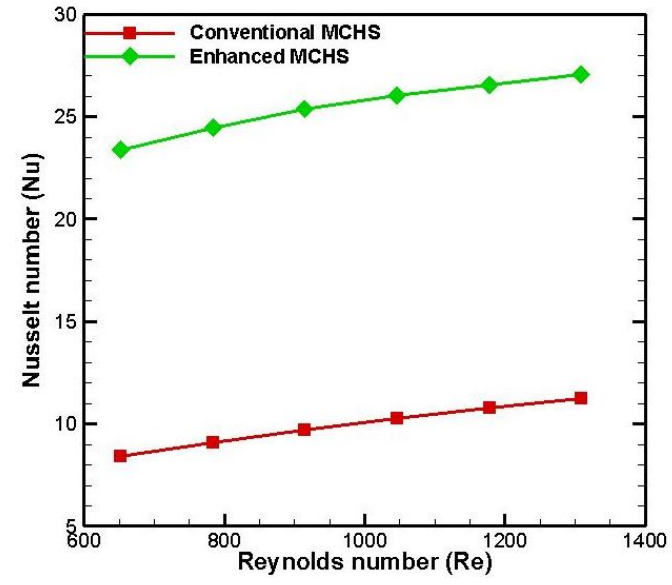

(b)

Figure 14. Variation of $\mathrm{Nu}$ with Re for heat flux of (a) 100 and (b) 200 Watt per sq.cm 


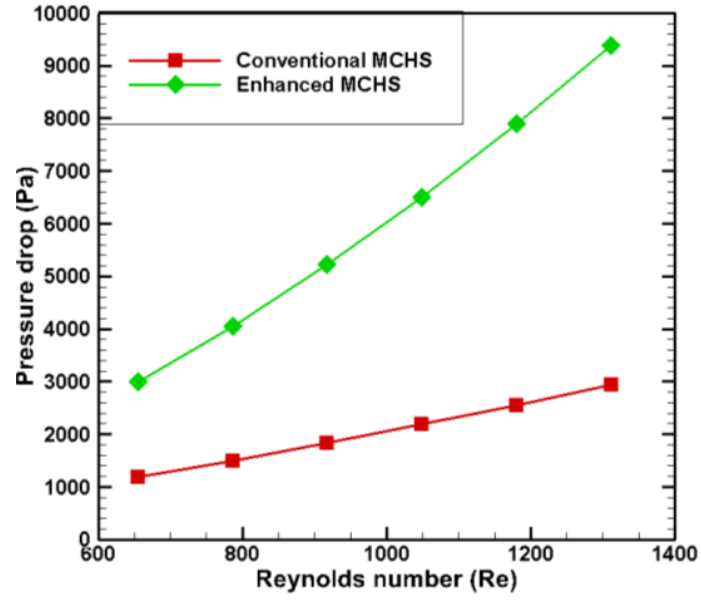

(a)

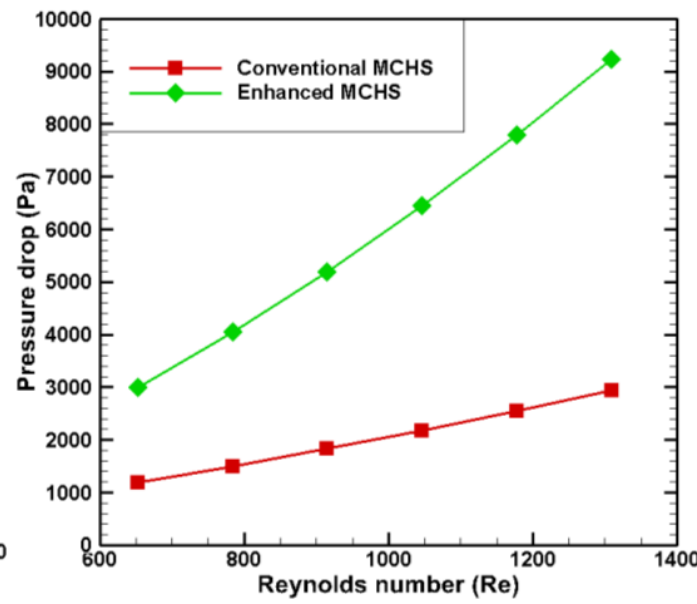

(b)

Figure 15. Variation of Pressure drop with Re for Heat flux of (a) 100 and (b) 200 Watt per sq.cm

The tendency of average bottom surface temperature against Reynolds number for both MCHS is shown in Figure 16. The average bottom surface temperature decreases with increase in flow rate for both MCHS. The bottom surface temperature indicates the temperature maintained of the component being cooled by the MCHS. Electronic cooling is one of the major applications of MCHS. The maximum operating temperature of the commercial electronic components is $343 \mathrm{~K}$ and is $358 \mathrm{~K}$ for industrial electronics components [25].The bottom surface temperature for conventional MCHS exceeds the maximum operating temperature for both heat fluxes. Enhanced MCHS bottom surface temperatures are below the maximum limit for a heat flux of 100 Watt per sq.cm, while for heat flux of 200 Watt per sq.cm, the bottom surface temperature is below the limit at higher flow rates only.

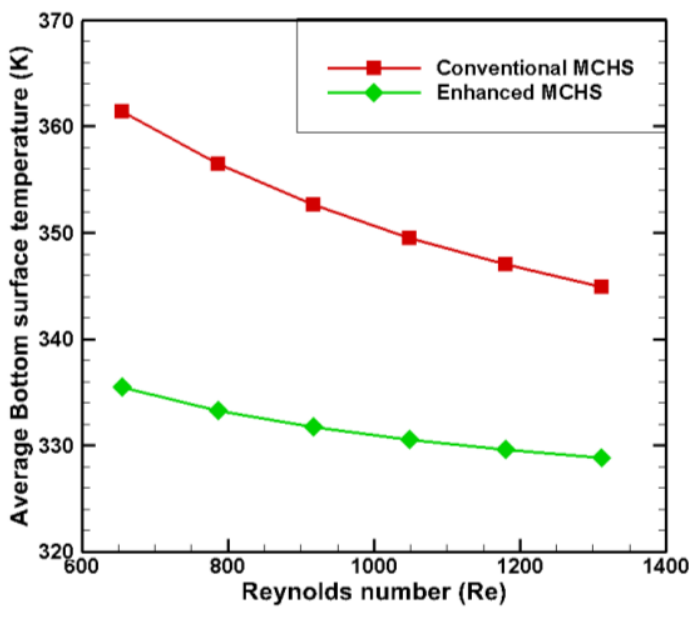

(a)

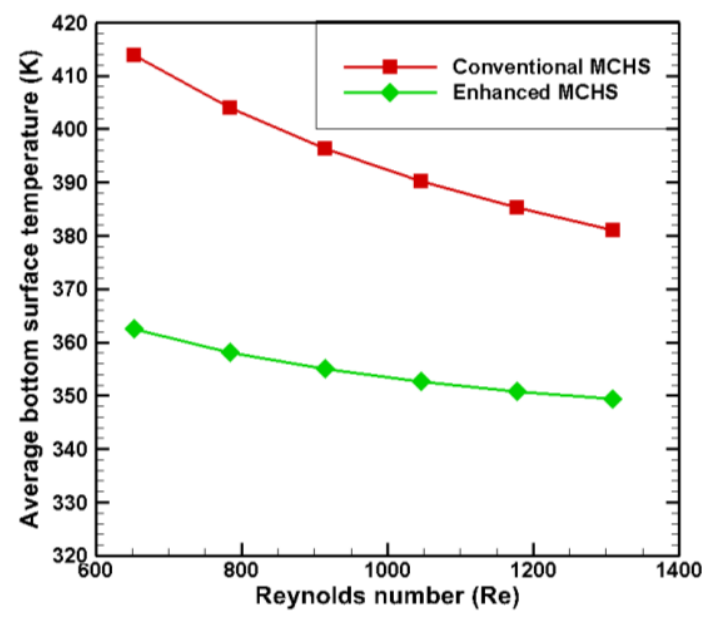

(b)

Figure 16. Variation of average bottom surface temperature with Re for Heat flux of (a) 100 and (b) 200 Watt per sq.cm 


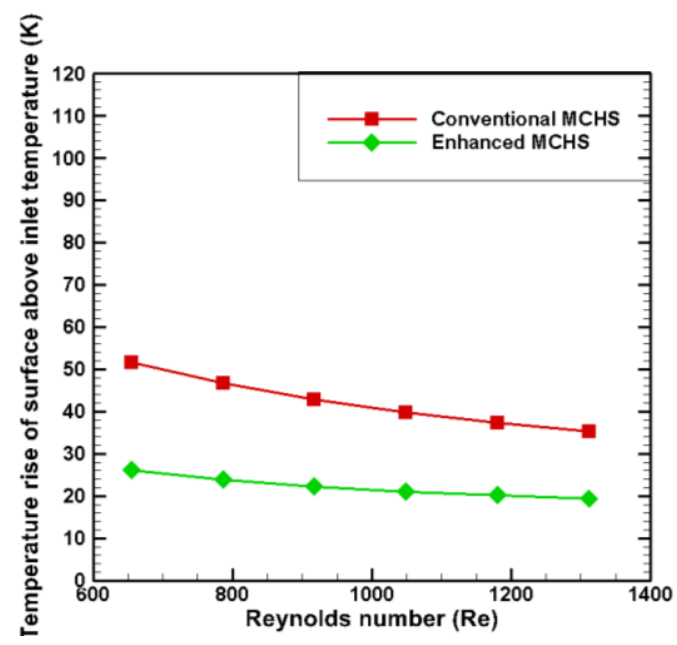

(a)

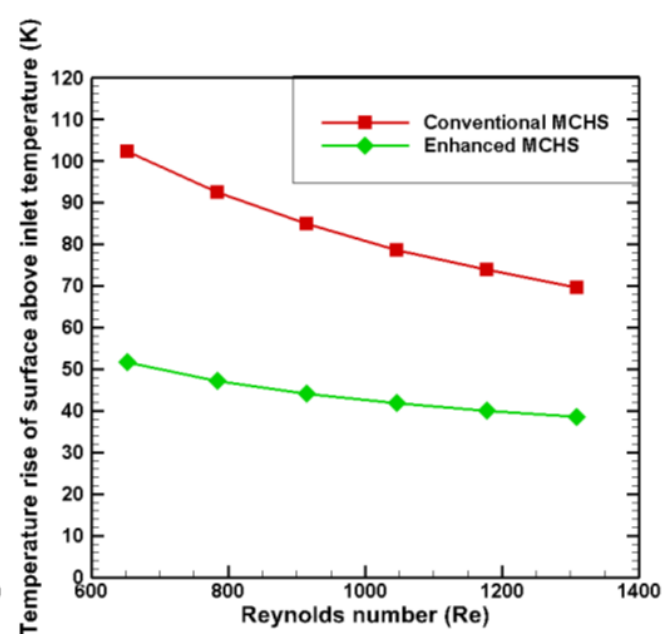

(b)

Figure 17. Variation of rise in surface temperature above fluid inlet temperature with Re for heat flux of (a) 100 and (b) 200 Watt per sq.cm

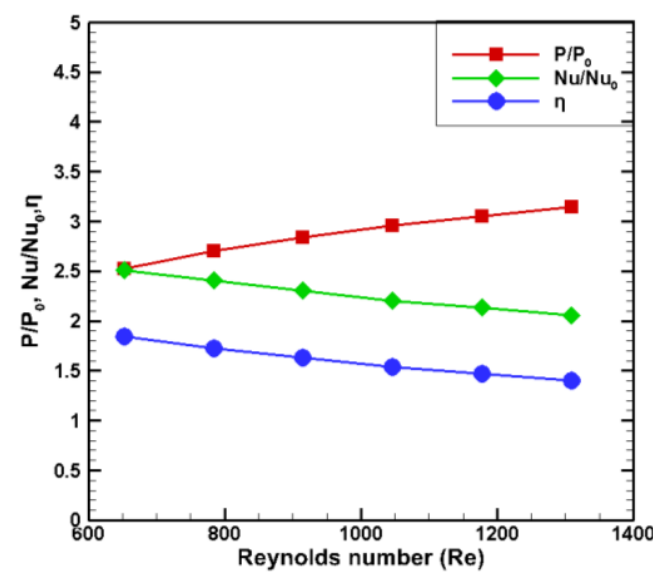

(a)

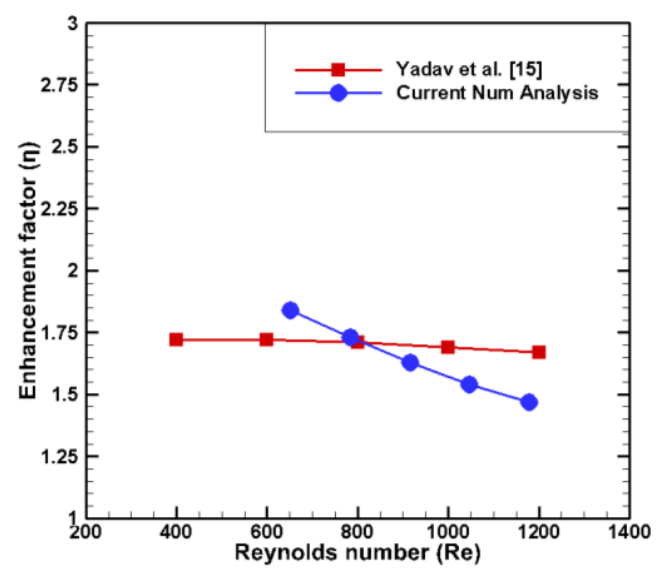

(b)

Figure 18. (a) Variation of pressure, Nusselt number ratios and enhancement factor with Reynolds number (' 0 ' indicates conventional MCHS) (b) Comparison of performance with Yadav et al. [15] for heat flux of $100 \mathrm{Watt} / \mathrm{cm}^{2}$

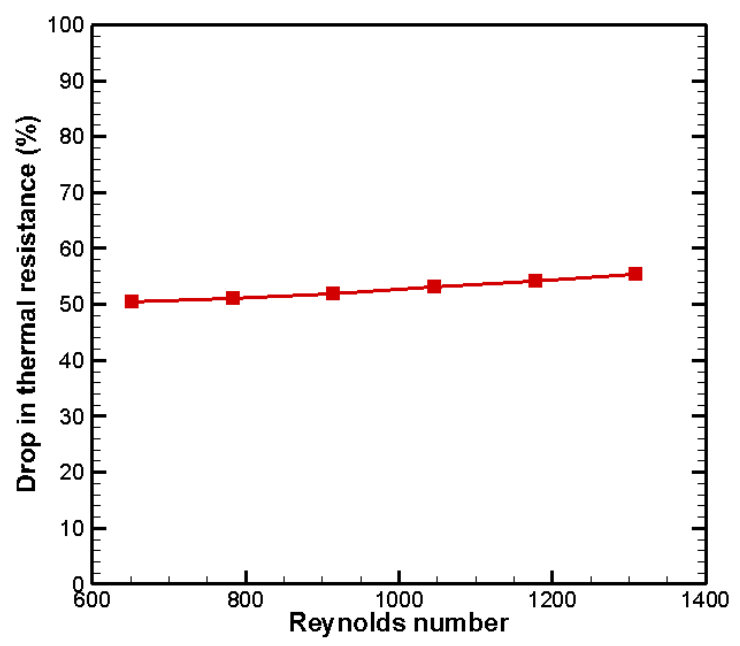

Figure 19. Variation of drop in thermal resistance for different Reynolds number 
Comparison of various parameters of enhanced MCHS with conventional MCHS is shown in Figure 18 a) with the subscript 0 indicating the values of conventional MCHS. The Nusselt number ratio decreases with higher Reynolds number. The $\mathrm{P} / \mathrm{P} 0$ ratio is the pressure drop factor which increases with higher Reynolds number. This is happening due to the condition of less flow through secondary channels at higher flow rates, as the flow does not get sufficient time to divert into secondary channels. Owing to the behavior of above two factors the enhancement factor also decreases with increase in Reynolds number but is more than one which means the overall performance of the enhanced MCHS is superior than conventional MCHS for all flow rates. The performance of current configuration is compared with recent work in extended microchannels (case I) by Yadav et al. [15] (Figure 18 b). The enhancement factor is similar at different Reynolds number, the variation is less than 10 percent. The variation can be attributed to the difference in the enhancement design employed in both cases. Figure 19 shows the percentage drop in thermal resistance $\left(\mathrm{R} / \mathrm{R}_{0}\right)$ in the enhanced MCHS compared to conventional MCHS for various Reynolds number. The thermal resistance is reduced by a minimum of 50 percent at low Reynolds number and by 55 percent for high Reynolds number.

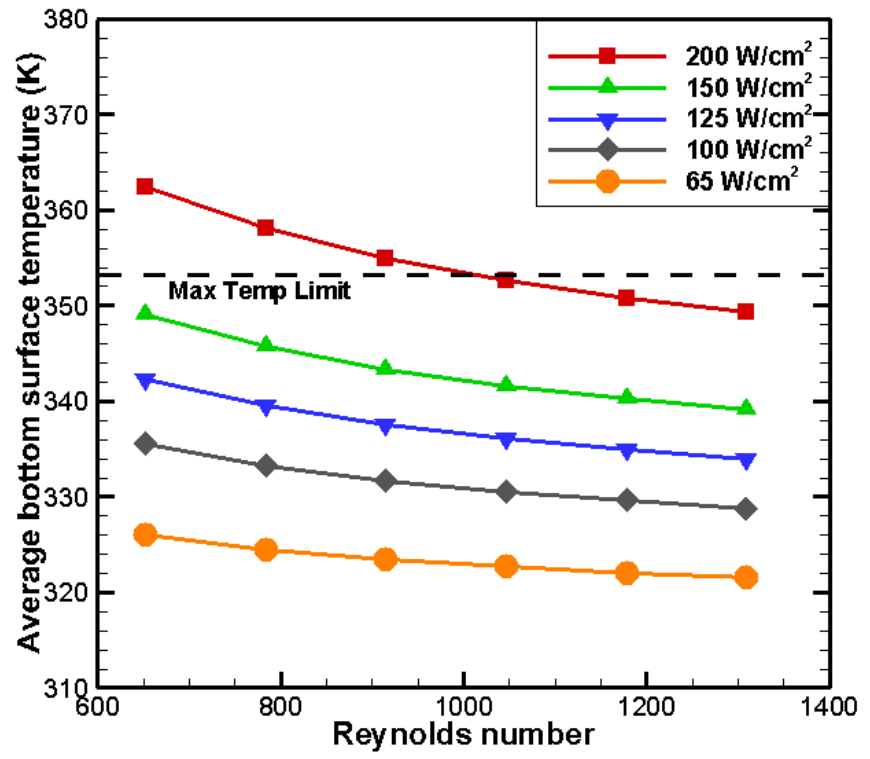

Figure 20. Average bottom surface temperature for different heat flux conditions

Conventional electronic components are required to operate over a specified temperature having an upper limit of $343 \mathrm{~K}$ for commercial applications and $358 \mathrm{~K}$ for industrial applications (22). Let us consider $353 \mathrm{~K}$ as the upper limit for the bottom surface of the MCHS which can be analogous to the electronic components being cooled by MCHS. Figure 18 shows the variation of average bottom surface temperature for enhanced MCHS subjected to various heat fluxes at different flow rates. The bottom surface temperature is above the limit only for heat flux of 200 Watt per sq.cm. For the remaining heat fluxes, the bottom surface temperature is below the limit. Thus, the enhanced MCHS are suitable for heat flux of 150 Watt per sq.cm and also for heat flux of 200 Watt per sq.cm but using higher flow rates.

\section{CONCLUSION}

The hydraulic and thermal performance of MCHS having secondary channels of leaf venation pattern is investigated numerically. The performance is compared with conventional MCHS having same dimensions. The following conclusions are drawn:

- The hydraulic and thermal boundary layers are repeatedly disturbed and redeveloped at a number of locations due to the presence of secondary channels of the leaf venation network. The diversion of some portion of flow into the secondary channel helps in fluid coming in contact of more surface area. Mixing of fluid and 
chaotic advection leads to better thermal performance. The overall enhancement in the performance of enhanced MCHS compared to conventional MCHS lies in the range of 1.4 to 1.85.

- Large pressure drop in enhanced MCHS compared to conventional MCHS can be attributed to the closing of outlet of central channel which is done to force the fluid to flow through the secondary channels. Some of the pressure drop is recovered by the secondary channels. To validate the closing of central channel outlet, the performance is compared with three outlets design in which it is observed that there is very little secondary flow in three outlets design.

- A proper mechanism for diverting the flow through the secondary channels which can be economically fabricated is needed to further improve the performance of MCHS.

- The use of secondary channels in leaf venation pattern results in surface temperature of the MCHS bottom which is lower than the limit of operating temperature of electronic components. The enhanced MCHS are suitable for cooling of electronic components having a heat flux of 200 Watt per sq.cm.

\section{NOMENCLATURE}

\begin{tabular}{|c|c|}
\hline A & Area \\
\hline $\mathrm{C}_{\mathrm{p}}$ & Specific heat, (kJ/kg K) \\
\hline $\mathrm{D}_{\mathrm{h}}$ & Hydraulic diameter, (mm) \\
\hline $\mathrm{f}$ & Friction factor \\
\hline $\mathrm{H}$ & Height of channel (mm) \\
\hline $\mathrm{h}$ & heat transfer coefficient, (W/sq. m K) \\
\hline $\mathrm{K}$ & Thermal conductivity (W/m K) \\
\hline $\mathrm{L}$ & Total channel length, (mm) \\
\hline $\mathrm{m}$ & mass flow rate, $(\mathrm{kg} / \mathrm{s})$ \\
\hline $\mathrm{Nu}$ & Nusselt number \\
\hline $\mathrm{P}$ & Pressure, $(\mathrm{Pa})$ \\
\hline$q^{\prime \prime}$ & Heat flux (W/sq. cm) \\
\hline $\mathrm{Re}$ & Reynolds number \\
\hline $\mathrm{T}$ & temperature, $\left(\mathrm{K},{ }^{\circ} \mathrm{C}\right)$ \\
\hline $\mathrm{U}_{\mathrm{m}}$ & mean velocity, $(\mathrm{m} / \mathrm{s})$ \\
\hline W & Width (mm) \\
\hline Po & Poiseuille number \\
\hline $\mathrm{R}$ & Thermal resistance \\
\hline \multicolumn{2}{|l|}{ Greek } \\
\hline$\Delta \mathrm{p}$ & Pressure drop \\
\hline$\Delta \mathrm{T} / \Delta \mathrm{Z}$ & Temperature gradient $(\mathrm{K} / \mathrm{mm})$ \\
\hline$\Delta \mathrm{T}$ & Temperature difference \\
\hline$\rho$ & density, (kg/cubic m) \\
\hline$\mu$ & viscosity, (Pa s) \\
\hline$\delta$ & Aspect ratio \\
\hline \multicolumn{2}{|c|}{ Subscripts } \\
\hline $\mathrm{m}$ & mean \\
\hline $\mathrm{i}$ & inlet \\
\hline o & outlet \\
\hline s & surface \\
\hline Max & maximum \\
\hline
\end{tabular}


Journal of Thermal Engineering, Research Article, Vol. 6, No. 5, pp. 677-696, October, 2020

$\begin{array}{cl}\text { C } & \text { channel } \\ \text { W } & \text { wall } \\ \text { App } & \text { apparent } \\ \text { Bottom } & \text { base } \\ \text { Conv } & \text { convective } \\ \text { Ave } & \text { average } \\ 0 & \text { conventional } \\ \text { F } & \text { fluid } \\ \text { Superscripts } \\ \text { “ } \quad \text { flux } \\ \text { * } \quad \text { Dimensionless length } \\ \text { Acronyms } \\ \text { MCHS } & \text { Microchannel heat sink }\end{array}$

\section{ACKNOWLEDGEMENTS}

The authors would like to thank the Government College of Engineering Karad, India and AICTE Delhi, India for the computing facility and experimental setup used for this work.

\section{REFERENCES}

[1] D. B. Tuckerman and R. F. W. Pease, "High-performance heat sinking for $\{$ VLSI $\}$," $\{$ IEEE $\}$ Electron Device Lett., vol. 2, no. 5, pp. 126-129, May 1981.

[2] M. Steinke and S. Kandlikar, "Review of single-phase heat transfer enhancement techniques for application in microchannels, minichannels and microdevices," Int. J. Heat Technol., vol. 22, pp. 3-11, 2004.

[3] L. Chai, G. Xia, M. Zhou, J. Li, and J. Qi, "Optimum thermal design of interrupted microchannel heat sink with rectangular ribs in the transverse microchambers," Appl. Therm. Eng., vol. 51, no. 1-2, pp. 880-889, Mar. 2013.

[4] G. Xie, F. Zhang, B. Sundén, and W. Zhang, "Constructal design and thermal analysis of microchannel heat sinks with multistage bifurcations in single-phase liquid flow," Appl. Therm. Eng., vol. 62, no. 2, pp. 791802, Jan. 2014.

[5] H. Shen, C.-C. Wang, and G. Xie, "A parametric study on thermal performance of microchannel heat sinks with internally vertical bifurcations in laminar liquid flow," Int. J. Heat Mass Transf., vol. 117, pp. 487-497, Feb. 2018.

[6] J. Lan, Y. Xie, and D. Zhang, "Flow and Heat Transfer in Microchannels With Dimples and Protrusions," $J$. Heat Transfer, vol. 134, no. 2, p. 21901, 2012.

[7] Y. Jia, G. Xia, Y. Li, D. Ma, and B. Cai, "Heat transfer and fluid flow characteristics of combined microchannel with cone-shaped micro pin fins," Int. Commun. Heat Mass Transf., vol. 92, pp. 78-89, Mar. 2018.

[8] P. Li, Y. Luo, D. Zhang, and Y. Xie, "Flow and heat transfer characteristics and optimization study on the water-cooled microchannel heat sinks with dimple and pin-fin," Int. J. Heat Mass Transf., vol. 119, pp. 152162, Apr. 2018.

[9] V. S. Duryodhan, A. Singh, S. G. Singh, and A. Agrawal, "Convective heat transfer in diverging and converging microchannels," Int. J. Heat Mass Transf., vol. 80, pp. 424-438, Jan. 2015.

[10] S. Soleimanikutanaei, E. Ghasemisahebi, and C.-X. Lin, "Numerical study of heat transfer enhancement using transverse microchannels in a heat sink," Int. J. Therm. Sci., vol. 125, pp. 89-100, Mar. 2018.

[11] Y. F. Li, G. D. Xia, D. D. Ma, Y. T. Jia, and J. Wang, "Characteristics of laminar flow and heat transfer in microchannel heat sink with triangular cavities and rectangular ribs," Int. J. Heat Mass Transf., vol. 98, pp. 17-28, Jul. 2016.

[12] N. R. Kuppusamy, R. Saidur, N. N. N. Ghazali, and H. A. Mohammed, "Numerical study of thermal enhancement in micro channel heat sink with secondary flow," Int. J. Heat Mass Transf., vol. 78, pp. 216223, Nov. 2014.

[13] Y. J. Lee, P. S. Lee, and S. K. Chou, "Enhanced Thermal Transport in Microchannel Using Oblique Fins," J. 
Heat Transfer, vol. 134, no. 10, p. 101901, 2012.

[14] I. A. Ghani et al., "Heat transfer enhancement in microchannel heat sink using hybrid technique of ribs and secondary channels," Int. J. Heat Mass Transf., vol. 114, pp. 640-655, Nov. 2017.

[15] V. Yadav, K. Baghel, R. Kumar, and S. T. Kadam, "Numerical investigation of heat transfer in extended surface microchannels," Int. J. Heat Mass Transf., vol. 93, pp. 612-622, Feb. 2016.

[16] S. A. Zunaid Mohammad, Jindal A, Gakhar D, "Numerical study of pressure drop and heat transfer in a straight rectangular and semi cylindrical projections microchannel heat sink," J. Therm. Eng., vol. 3, no. 5, pp. 1453-1465, Sep. 2017.

[17] R. S. Belhadj, Abdelkadir, R. Bouchenafa, "A numerical study of forced convective flow in microchannels heat sinks with periodic expansion-constriction cross section," J. Therm. Eng., pp. 1912-1925, Mar. 2018.

[18] C. A. Rubio-Jimenez, S. G. Kandlikar, and A. Hernandez-Guerrero, "Performance of Online and Offset Micro Pin-Fin Heat Sinks With Variable Fin Density," \{IEEE\} Trans. Components, Packag. Manuf. Technol., vol. 3, no. 1, pp. 86-93, Jan. 2013.

[19] X. Q. Wang, P. Xu, A. S. Mujumdar, and C. Yap, "Flow and thermal characteristics of offset branching network," Int. J. Therm. Sci., vol. 49, no. 2, pp. 272-280, 2010.

[20] Frank P. Incropera, Liquid Cooling of electronic devices by single phase convection. John Wiley \& Sons, 1999.

[21] P. S. Lee, S. V. Garimella, and D. Liu, "Investigation of heat transfer in rectangular microchannels," Int. J. Heat Mass Transf., vol. 48, no. 9, pp. 1688-1704, 2005.

[22] M. E. Steinke and S. G. Kandlikar, "Single-phase liquid friction factors in microchannels," Int. J. Therm. Sci., vol. 45, no. 11, pp. 1073-1083, Nov. 2006.

[23] R. L. Webb, "Performance evaluation criteria for use of enhanced heat transfer surfaces in heat exchanger design," Int. J. Heat Mass Transf., vol. 24, no. 4, pp. 715-726, Apr. 1981.

[24] R. K. Shah, Laminar Flow Forced Convection in Ducts: A Source Book for Compact Heat Exchanger Analytical Data (Advances in Heat Transfer. Supplement). Academic Pr, 1978.

[25] L. Condra et al., "Terminology for use of parts outside manufacturer-specified temperature ranges," $\{$ IEEE $\}$ Trans. Components Packag. Technol., vol. 22, no. 3, pp. 355-356, Sep. 1999. 